\title{
Microencapsulation of L-Ascorbic Acid by Spray Drying Using Sodium Alginate as Wall Material
}

\author{
Ferrándiz Marcela1 ${ }^{1}$, Capablanca Lucía ${ }^{2}$, Franco Esther ${ }^{1}$, Mira Elena ${ }^{1}$ \\ ${ }^{1}$ Biotechnology Research Group, Textile Research Institute (AITEX), Alcoy, Spain \\ ${ }^{2}$ Polytechnic University of Valencia (UPV), Campus de Alcoy, Alcoy, Spain \\ Email:mferrandiz@aitex.es, lucafra@upvnet.upv.es
}

Received 16 December 2015; accepted 29 February 2016; published 2 March 2016

Copyright (C) 2016 by authors and Scientific Research Publishing Inc.

This work is licensed under the Creative Commons Attribution International License (CC BY). http://creativecommons.org/licenses/by/4.0/

(c) (i) Open Access

\begin{abstract}
L-ascorbic acid is a water soluble vitamin (vitamin C) widely used as an additive in foods and cosmetics. It has high instability against certain environmental factors; the main cause of its deterioration is oxidation. Microencapsulation is an effective protection technique of L-ascorbic acid from its degradation reactions. This work is focused on the encapsulation of L-ascorbic acid by spray drying technique using sodium alginate as wall material. The microcapsules morphology was observed by scanning electron microscopy (SEM) and the encapsulation efficiency was determined by spectrophotometric analysis. Results showed that encapsulation efficiency was of $\mathbf{9 3 . 4 8 \%}$ and after 30 days was of $\mathbf{9 2 . 5 5 \%}$; differences were not significant, so that the stability of L-ascorbic acid was not affected. Encapsulation yields obtained were low, at around $30 \%$, but the microcapsules morphology obtained is spherical.
\end{abstract}

\section{Keywords}

L-Ascorbic Acid, Sodium Alginate, Spray Drying, Microencapsulation, Stability

\section{Introduction}

Vitamin $\mathrm{C}$ is also known as ascorbic acid, it is an ingredient/additive commonly used in food and cosmetic industry by virtue of its properties. It is a water soluble vitamin which acts as an oxidizer and free radical scavenger [1]. Vitamin $\mathrm{C}$ is called antioxidant because of its ability of quenching or stabilizing free radicals that lead over time to degenerative diseases, including cardiovascular cancer, cataracts and other diseases [2] [3].

Its application is limited due to its instability, which is influenced by several factors; it is strongly influenced 
by catalytic reactions by the transition of metal ions, such as $\mathrm{Cu}^{2+}$ and $\mathrm{Fe}^{3+}$, heat, light, $\mathrm{pH}$ (in alkaline media), high oxygen concentration and high water activity, all of which results in the increase of both the solubility of the ascorbic acid and the oxygen dissolution. Ascorbic acid degradation is also associated with a loss of color both in the presence and absence of amines [4]-[6].

Microencapsulation of ascorbic acid is an alternative of its protection, improving at the same time its stability. Microencapsulation is one of the wide applications of biopolymers that help to protect specific functional materials from, or to release them into the outer phase for a long period [7].

Microencapsulation of biomolecules has become a challenging approach to design new materials used in food and pharmaceutical industries to improve stability, delivery and to control the release of encapsulated species. Biopolymers like alginate, chitosan and Arabic gum have attracted interest as wall materials and have been applied in the pharmaceutical, food, biomedical, chemical, and waste-treatment industries [8].

Alginate is biopolymer used as biomaterial; it is derived from brown seaweeds such as Laminiaria digitate and Laminiaria hyperboria and it shares a chemical structure similar to the polysaccharide components of the extracellular matrix. It is currently processed as high purity and low toxicity biocompatible polymer [9] [10].

Alginates have been applied for several applications related to microencapsulation and controlled release delivery systems. Alginate gel structure is relatively stable at acidic $\mathrm{pH}$, but it is easily swollen and disintegrated under mild alkali conditions [10].

Spray-drying is one of the several techniques for ascorbic acid encapsulation. By this method an emulsion is sprayed into the air by atomization, usually at elevated temperatures to evaporate the solvent. The selection of a suitable wall material is critical to a microencapsulation spray-drying process to avoid changes due to oxidation or chemical interactions [11] and maximize the retention of ascorbic acid after the drying process is completed. Furthermore the mass relation between wall and shell materials is a variable to optimize in the process [12].

Spray drying has many advantages including economy, easy control of microsphere properties by changing the operational parameters, the convenience in scale-up, etc. [13]. The quality attributes of microcapsules could be affected by the spray drying conditions such as feed flow rate, inlet and outlet temperature, suction power, etc. [14] [15]. It is important to optimize the inlet and outlet temperatures to obtain higher encapsulation efficiency (EE) and encapsulation yield (EY) [14]. Higher inlet temperature may destroy heat sensitive components and if the inlet temperature is too low, the water emulsion will not evaporate.

The aim of this work is the encapsulation of ascorbic acid by spray drying technique using sodium alginate as wall material. Parameters such as inlet temperature, suction power and mass relation between alginate and ascorbic acid will be optimized in order to obtain microcapsules with adequate morphology and high encapsulation efficiency and encapsulation yields. Scanning electron microscopy allows to know the microcapsules morphology.

\section{Materials and Methods}

\subsection{Materials}

A low viscosity alginic acid sodium salt from brown algae (supplied by Sigma Aldrich, Spain) was used as shell material.

The core material was L-ascorbic acid (supplied by Sigma Aldrich, Spain).

\subsection{Emulsion Preparation}

The alginate solution was prepared with $3.5 \%(\mathrm{w} / \mathrm{w})$. The alginic acid sodium salt was mixed with distilled water and kept in the refrigerator during $24 \mathrm{~h}$, in order to obtain the right viscosity and stabilize the emulsion.

The mass relation between $\mathrm{L}$-ascorbic acid and sodium alginate was: 1:3.5, 2:3.5 and 2.5:3.5.

Emulsions were prepared at a constant agitation speed of $1200 \mathrm{rpm}$, during $10-15 \mathrm{~min}$ at room temperature.

Emulsion compositions are shown in Table 1.

\subsection{Microencapsulation by Spray Drying}

Spray-drying was performed using a spray-dryer BÜCHI B-290 (BÜCHI, Switzerland) with a standard $0.7 \mathrm{~mm}$ nozzle. It consists in four separate stages [16], as can be seen in Figure 1.

During the atomization of the fluid into the drying chamber (3), the liquid droplets with high surface to mass ratio and to uniformly and quickly evaporate the water. The drying process of such droplets is very rapid with an 
Table 1. Experimental conditions.

\begin{tabular}{ccccccc}
\hline & \multicolumn{2}{c}{$\begin{array}{c}\text { Emulsion components } \\
\text { (mass ratio) }\end{array}$} & \multicolumn{3}{c}{ Spray dried conditions } \\
\cline { 2 - 7 } Experiment & $\begin{array}{c}\text { L-ascorbic } \\
\text { acid }\end{array}$ & $\begin{array}{c}\text { Sodium } \\
\text { alginate }\end{array}$ & $\begin{array}{c}\text { Inlet } \\
\text { temperature }\left({ }^{\circ} \mathbf{C}\right)\end{array}$ & $\begin{array}{c}\text { Feed flow rate } \\
(\mathbf{\%})\end{array}$ & $\begin{array}{c}\text { Suction power } \\
(\%)\end{array}$ & $\begin{array}{c}\text { Air flow rate } \\
(\mathbf{c m})\end{array}$ \\
\hline 1 & 1.0 & 3.5 & 110 & 20 & 70 & 4 \\
2 & 1.0 & 3.5 & 125 & 20 & 70 & 4 \\
3 & 1.0 & 3.5 & 110 & 20 & 65 & 4 \\
4 & 2.5 & 3.5 & 110 & 20 & 65 & 4 \\
5 & 2.0 & 3.5 & 110 & 20 & 65 & 4 \\
\hline
\end{tabular}

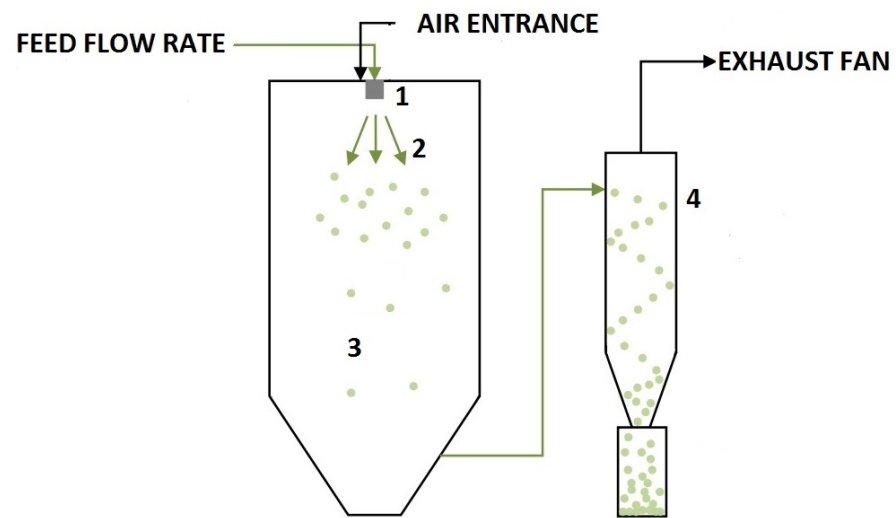

Figure 1. Spray drying technique: 1) atomization of feed; 2) spray-air contact; 3) drying; 4) separation of the dried product from the drying air.

intensive moisture evaporation at the surface of the droplets, which keep the droplets cool until the dry state is reached [17].

The experimental parameters are showed in Table 1.

\section{Characterization Tests}

\subsection{Determination of Microcapsules Morphology. Scanning Electron Microscopy (SEM)}

For microcapsules surface observation, a PHENON scanning electron microscope (FEI Company, United States) was used. Each sample was fixed on a standard sample holder and sputter coated with gold. Samples were then examined with suitable acceleration voltage and magnification.

\subsection{Determination of Encapsulation Yield (EY\%)}

EY was calculated as ratio of the weight of the resultant powder after spray drying in collecting bottle and the weight of all solids (including wall and core materials) in the emulsion, expressed as percentage.

Any microcapsules adhering to the walls of the drying chamber or cyclone were not considered, so this yield will be only approximate.

\subsection{Determination of Encapsulation Efficiency (EE\%)}

The ascorbic acid encapsulation efficiency was calculated by the following equation:

$$
\mathrm{EE}(\%)=\frac{\text { Total ascorbic acid content }(\mathrm{g})-\text { Surface ascorbic acid content }(\mathrm{g})}{\text { Total ascorbic acid content }(\mathrm{g})} \times 100
$$


The Total ascorbic acid content and Surface ascorbic acid content were determined by spectrophotometry using a spectrophotometer UV-vis-NIR Cary 5000 (Agilent Technologies, USA).

First, ascorbic acid/alginate (optimum mass ratio) solutions were dissolved in water or ethanol at different concentrations in order to obtain the calibration curves. Wavelengths selected for quantification study were 264 $\mathrm{nm}$ (water) and $245 \mathrm{~nm}$ (ethanol).

Surface ascorbic acid content was determined by washing $1 \mathrm{~g}$ of microcapsules with $30 \mathrm{~mL}$ of distilled water. The solution was analyzed in the spectrophotometer at the corresponding wavelength $(264 \mathrm{~nm})$, and interpolated on the calibration curve. It was necessary to dilute the samples (400 times) in order to fit in the calibration curve.

Microcapsules increased their weight because the alginate was hydrated [18], for this reason it was considered an half of a $94 \%$ water-swollen [18]. Value is to be considered in the calculation of encapsulation efficiency.

Total ascorbic acid content was determined by dissolving the washed microcapsules in $10 \mathrm{~mL}$ of ethanol. The mix was centrifuged at $3000 \mathrm{rpm}$ during 5 minutes and it was allowed to stand for decantation during 30 minutes. The solution was analyzed in the spectrophotometer at the corresponding wavelength $(245 \mathrm{~nm})$, and interpolated on the calibration curve. It was necessary to dilute the samples (40 times) in order to fit in the calibration curve.

In order to know if the microcapsules protect the L-ascorbic acid over time, the encapsulation efficiency was determined 30 days after the production process.

\section{Results and Discussion}

\subsection{Microcapsules Morphology. Scanning Electron Microscopy (SEM)}

The morphology of the microcapsules was studied by scanning electron microscopy (SEM). Figure 2 shows the micrographs of ascorbic acid microcapsules.

Figure 2 shows that when the temperature and suction power decrease, the microcapsules morphology is more spherical. Furthermore the mass ratio has an important influence in the microcapsules morphology.

Using the mass ratio 2.0:3.5 (L-ascorbic acid/alginate) the best results are obtained.

\subsection{Determination of Encapsulation Yield (EY\%)}

Table 2 shows the encapsulation yield of the experiments. Encapsulation yield decreases when the morphology is correct, spherical. Also when the inlet temperature and suction power decreases and the mass ratio increases the yield is lower. This may be because low inlet temperature and suction power will result in a low evaporation rate, which causes the formation of microcapsules with high water content, poor fluidity, and ease of agglomeration. Furthermore, with these conditions, additional high amount of particles remain on the wall of the drying chamber and they are not collected.

Using the mass ratio 2.0:3.5 (L-ascorbic acid/alginate) the encapsulation yield is lower but the microcapsules morphology is corrected.

\subsection{Determination of Encapsulation Efficiency (EE\%)}

\subsubsection{Surface Ascorbic Acid Content}

Surface ascorbic acid content was determined by washing $1 \mathrm{~g}$ of microcapsules with $30 \mathrm{~mL}$ of distilled water. The solution was analyzed in the spectrophotometer at the corresponding wavelength $(264 \mathrm{~nm})$, and interpolated on the calibration curve. It was necessary to dilute the samples (400 times) in order to fit in the calibration curve.

The equation for the calibration curve (microcapsules dissolved in water) was the following:

$$
y=0.0685 x+0.0456\left(R^{2}=0.9988\right)
$$

where, $x=$ concentration $\left(\mu \mathrm{g} \cdot \mathrm{mL}^{-1}\right)$

Spectrophotometric measures were carried out at initial time (0) and after 30 days.

For the results it has been considered the experiment 5 as the optimum one, and the mass ratio 2.0:3.5 (L-ascorbic acid/alginate).

$\%$ Oil non-encapsulated lost in the wash is calculated considering the ascorbic acid weight in $30 \mathrm{~mL}$ wash, and the quantity of ascorbic acid in $1 \mathrm{~g}$ of microcapsules, mass ratio 2.0:3.5 (L-ascorbic acid/alginate).

Oil quantity lost in the washing process is not significant in both tests. 


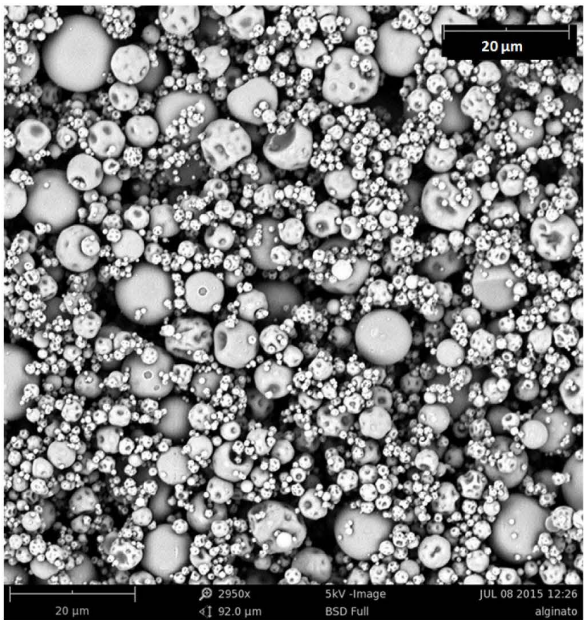

(a) $4000 \times$

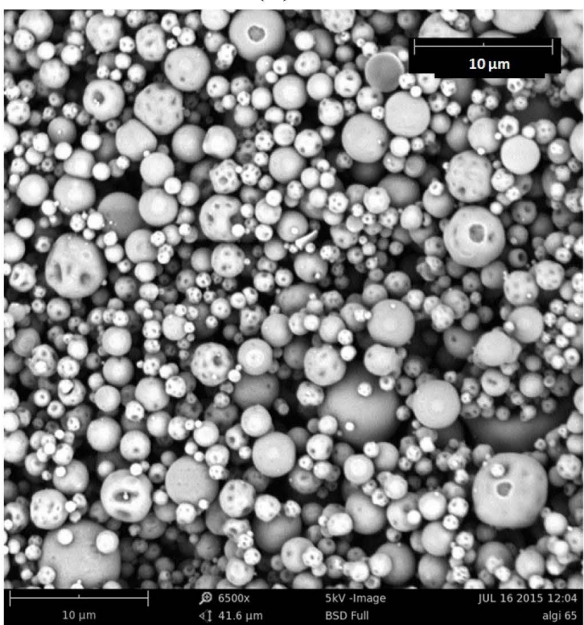

(c) $6500 \times$

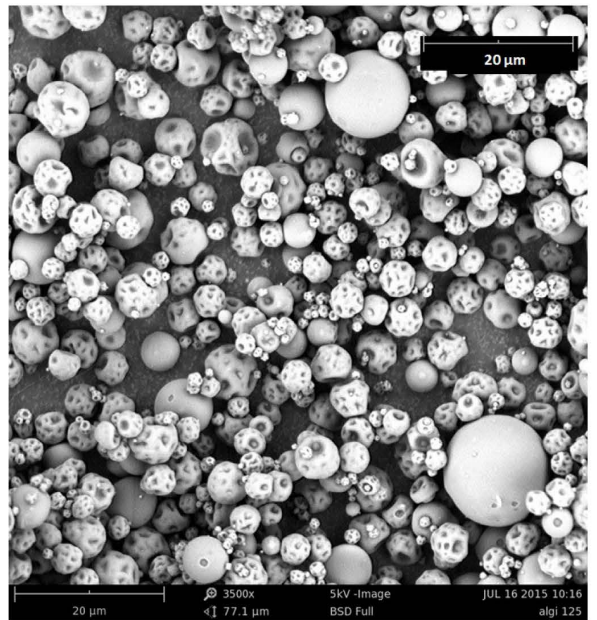

(b) $3500 \times$

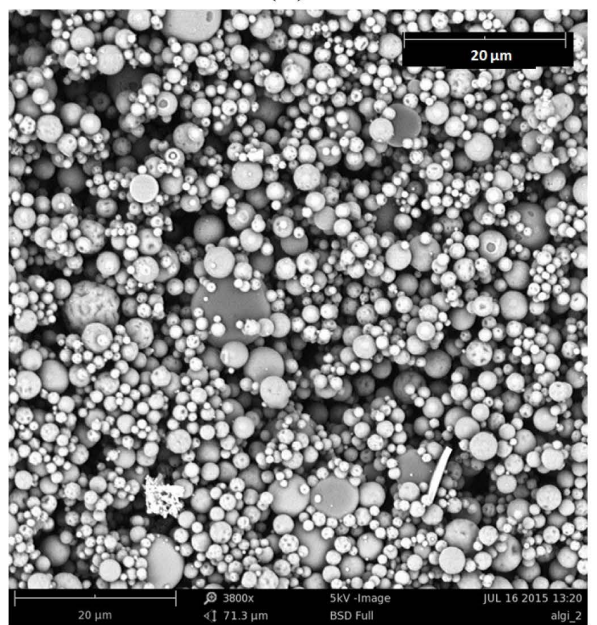

(d) $3800 \times$

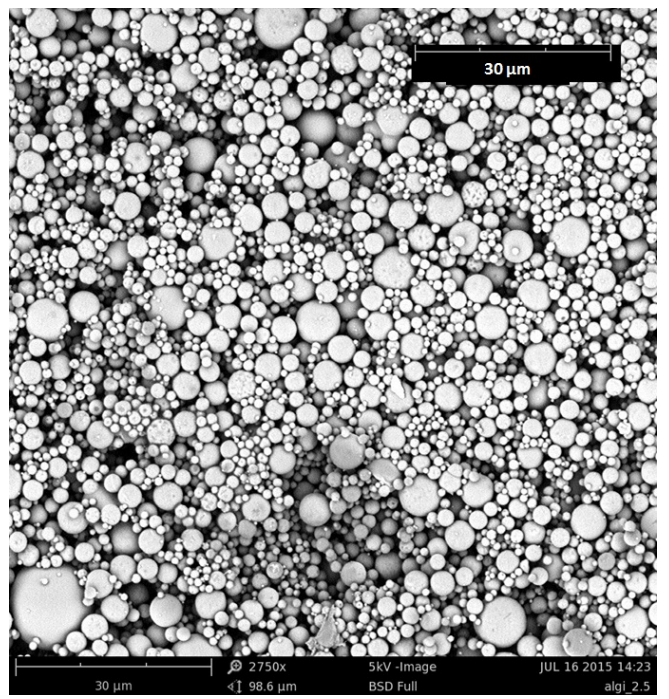

(e) $2750 \times$

Figure 2. SEM photographs of L-ascorbic microcapsules: (a) Experiment 1; (b) Experiment 2; (c) Experiment 3; (d) Experiment 4; (e) Experiment 5. 


\subsubsection{Total Ascorbic Acid Content}

After the washing process, microcapsules were dissolved in ethanol. Microcapsules increase their weight in contact with water. Total microcapsules weight has been corrected by the percent swelling found in the scientific literature [18] for this type of material (94\%).

Total ascorbic acid content was calculated by dividing the ascorbic acid quantity determined by spectrophotometry to the theoretically quantity of ascorbic acid held in $1 \mathrm{~g}$ microcapsules, considering the mass ratio between ascorbic acid:alginate (2.0:3.5).

Three replicates were performed.

The analysis carried was put in three samples at (0) time and after 30 days.

Values of total ascorbic acid inside the microcapsules are high and the differences after 30 days are not significant.

\subsubsection{Encapsulation Efficiency}

The ascorbic acid encapsulation efficiency calculated according to the results obtained in Tables 3-5 was:

Table 2. Encapsulation yields.

\begin{tabular}{|c|c|c|c|c|c|}
\hline \multirow{2}{*}{ Experiment } & \multicolumn{2}{|c|}{$\begin{array}{c}\text { Emulsion components } \\
\text { (mass ratio) }\end{array}$} & \multicolumn{2}{|c|}{ Spray dried conditions } & \multirow{2}{*}{ Encapsulation yield (\%) } \\
\hline & L-ascorbic acid & $\begin{array}{l}\text { Sodium } \\
\text { alginate }\end{array}$ & $\begin{array}{c}\text { Inlet } \\
\text { temperature }\left({ }^{\circ} \mathrm{C}\right)\end{array}$ & $\begin{array}{c}\text { Suction power } \\
(\%)\end{array}$ & \\
\hline 1 & 1.0 & 3.5 & 110 & 70 & 60.65 \\
\hline 2 & 1.0 & 3.5 & 125 & 70 & 59.74 \\
\hline 3 & 1.0 & 3.5 & 110 & 65 & 27.52 \\
\hline 4 & 2.0 & 3.5 & 110 & 65 & 30.36 \\
\hline 5 & 2.5 & 3.5 & 110 & 65 & 32.12 \\
\hline
\end{tabular}

Table 3. Surface ascorbic acid content, washing process.

\begin{tabular}{cccc}
\hline Sample & $\begin{array}{c}\text { Washing concentration } \\
\left(\mathbf{m g} \cdot \mathbf{m L}^{-1}\right)\end{array}$ & $\begin{array}{c}\text { Ascorbic acid weight } \\
\text { in 30 } \mathbf{~ m L} \text { wash }(\mathbf{m g})\end{array}$ & $\begin{array}{c}\text { \% Oil non-encapsulated lost in } \\
\text { the wash }\end{array}$ \\
\hline Initial 0 & 0.00731 & 0.0219 & 6.0 \\
After 30 days & 0.00810 & 0.0243 & 7.0 \\
\hline
\end{tabular}

Table 4. Surface ascorbic acid content, time 0.

\begin{tabular}{ccc} 
Sample & Ascorbic acid concentration $\left(\mathbf{m g} \cdot \mathbf{m L}^{-\mathbf{1}}\right)$ & Total ascorbic acid (\%) \\
\hline 1 & 0.3325 & 91.6 \\
2 & 0.3633 & 100.0 \\
3 & 0.3118 & 85.9 \\
Average & & $92.0 \pm 5$ \\
\hline
\end{tabular}

Table 5. Surface ascorbic acid content, after 30 days.

\begin{tabular}{|c|c|c|}
\hline Sample & Ascorbic acid concentration $\left(\mathrm{mg} \cdot \mathrm{mL}^{-1}\right)$ & Total ascorbic acid (\%) \\
\hline 1 & 0.3579 & 98.6 \\
\hline 2 & 0.3459 & 95.3 \\
\hline 3 & 0.3180 & 87.6 \\
\hline Average & & $94 \pm 6$ \\
\hline
\end{tabular}


Table 6. Encapsulation efficiency.

\begin{tabular}{cccc}
\hline Sample & Total ascorbic acid (\%) & Encapsulated lost in the wash (\%) & Encapsulation efficiency (\%) \\
\hline 0 & 92 & 6.0 & 93.48 \\
30 & 94 & 7.0 & 92.55 \\
\hline
\end{tabular}

Encapsulation of L-ascorbic acid with sodium alginate provides high encapsulation efficiency values, after 30 days, the values are similar.

\section{Conclusions}

Microencapsulation of L-ascorbic acid by spray drying technology using sodium alginate as wall material provides high results of encapsulation efficiencies. Microcapsules with spherical morphologies can be obtained. Because of the emulsion nature the yield values are not high, but the morphology is adequate.

After 30 days, no significant differences between encapsulation efficiency values (ANOVA, $p<0.05$ ) were determined, so it can be stated that the acid is not oxidized in this period of time.

\section{Acknowledgements}

The authors thank for technical and human support provided by Dr. L. Bartolomé from SGIKER of UPV/EHU, and for the financial support provided by IVACE (Institut Valencià de Competitivitat Empresarial, Spain) and FEDER (Fondo Europeo de Desarrollo Regional, Europe).

\section{References}

[1] Pulido, A. and Beristain, C.I. (2010) Spray Dried Encapsulation of Ascorbic Acid Using Chitosan as Wall Material. Revista Mexicana de Ingeniería Química, 9, 189-195.

[2] Eliott, J.G. (1999) Application of Antioxidants Vitamins in Food and Beverages. Food Technology, 53, 46-48.

[3] Hamilton, I.M.J. and Gilmore, W.S. (2000) Interactions between Vitamins C and E in Human Subjects. British Journal of Nutrition, 84, 261-267. http://dx.doi.org/10.1017/S0007114500001537

[4] Comunian, T.A., Abbaspourrad, R., Favaro-Trindade, C.S. and Weitz, D.A. (2014) Fabrication of Solid Lipid Microcapsules Containing Ascorbic Acid Using a Microfluidic Technique. Food Chemistry, 152, 271-275. http://dx.doi.org/10.1016/j.foodchem.2013.11.149

[5] Comunian, T.A., Thomazini, M., Alves, A.J.G., Junior, F.E.D., de Carvalho Balieiro, J. and Favaro-Trindare, C.S. (2013) Microencapsulation Ascorbic Acid by Complex Coacervation: Protection and Control Release. Food Research International, 52, 373-379. http://dx.doi.org/10.1016/j.foodres.2013.03.028

[6] Ukhum, M.E. and Dibie, E.N. (1991) The Ascorbic Acid Contents of Selected Marketed Foods and Influence of Water Activity $\left(\mathrm{A}_{\mathrm{w}}\right)$ during Storage. Food Chemistry, 41, 277-283. http://dx.doi.org/10.1016/0308-8146(91)90053-Q

[7] Hong, K. and Park, S. (1999) Preparation of Polyuria Microcapsules with Different Composition Ratios: Structures and Thermal Properties. Materials Science and Engineering, A272, 418-421.

[8] Ghanem, A. and Skonberg, D. (2002) Effect of Preparation Method on the Capture and Release of Biologically Active Molecules in Chitosan Gel Beads. Journal of Applied Polymer Science, 84, 405-413. http://dx.doi.org/10.1002/app.10393

[9] Mata, E., Igartua, M., Patarroyo, M.E., Pedraz, J.L. and Hernández, R.M. (2011) Enhancing Immunogenicity to PLGA Microparticulate Systems by Incorporation of Alginate and RGD-Modified Alginate. European Journal of Pharmaceutical Sciences, 44, 32-40. http://dx.doi.org/10.1016/j.ejps.2011.05.015

[10] Yoo, S.-H., Song, Y.-B., Chang, P.-S. and Lee, H.G. (2006) Microencapsulation of Alphatocopherol Using Sodium Alginate and Its Controlled Release Properties. International Journal of Biological Macromolecules, 38, 25-30. http://dx.doi.org/10.1016/j.ijbiomac.2005.12.013

[11] Botrel, D.A., Borges, S.V., Fernandes, R.V., Viana, A.D., Costa, J.M. and Marques, G. (2012) Evaluation of Spray Drying Conditions on Properties of Microencapsulated Oregano Essential Oil. International Journal of Food Science and Technology, 47, 2289-2296. http://dx.doi.org/10.1111/j.1365-2621.2012.03100.x

[12] Capablanca, L., Bonet, M., Bou, E., Ferrándiz, M., Franco, E. and Dolçà, C. (2014) Aplicación de técnicas biotecnológicas y de microencapsulación para la funcionalización de agrotextiles. Presented at the II Congreso I+D+i, Campus de Alcoy, Creando Sinergias, Alcoy. 
[13] Ye, M., Kim, S. and Park, K. (2010) Issues in Long-Term Protein Delivery Using Biodegradable Microparticles. Journal of Controlled Release: Official Journal of the Controlled Release Society, 146, 241-260. http://dx.doi.org/10.1016/j.jconrel.2010.05.011

[14] Kha, T.C., Nguyen, M.H., Roach, P.D. and Stathopoulos, C.E. (2014) Microencapsulation of Gac Oil: Optimization of Spray Drying Conditions Using Response Surface Methodology. Powder Technology, 264, 298-309. http://dx.doi.org/10.1016/j.powtec.2014.05.053

[15] Liu, Z.Q., Zhou, J.H., Zeng, Y.L. and Ouyang, X.L. (2004) The Enhancement and Encapsulation of Agaricus bisporus flavor. Drying Technology, 65, 391-396.

[16] Deis, R.C. (1997) Spray-Drying Innovative Use of an Old Process. Food Product Design, 7, 97-113.

[17] Vidović, S.S., Vladić, J.Z., Vaštag, Z.G., Zeković, Z.P. and Popović, L.M. (2014) Maltodextrin as a Carrier of Health Benefit Compounds in Satureja montana Dry Powder Extract Obtained by Spray Drying Technique. Powder Technology, 258, 209-215. http://dx.doi.org/10.1016/j.powtec.2014.03.038

[18] Díaz, D.E., Apocada, E., Villaran, M.C., Río, F., Ramirez, C.A. and Lorenoz, L. (2007) Utilización de adsorbentes basados en quitosano y alginato sódico para la eliminación de iones metálicos: $\mathrm{Cu}^{2+}, \mathrm{Pb}^{2+}, \mathrm{Cr}^{3+}$ y $\mathrm{Co}^{+}$. Revista Iberoamericana de Polímeros, 8, 20-37. 